\title{
Detailed Analysis of the Composition of Selected Plastic Packaging Waste Products and Its Implications for Mechanical and Thermochemical Recycling
}

\author{
Martijn Roosen, Nicolas Mys, Marvin Kusenberg, Pieter Billen, Ann Dumoulin, Jo Dewulf, \\ Kevin M. Van Geem, Kim Ragaert, and Steven De Meester*
}

Cite This: Environ. Sci. Technol. 2020, 54, 13282-13293

Read Online

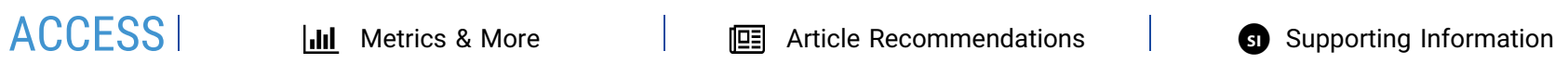

ABSTRACT: Plastic packaging typically consists of a mixture of polymers and contains a whole range of components, such as paper, organic residue, halogens, and metals, which pose problems during recycling. Nevertheless, until today, limited detailed data are available on the full polymer composition of plastic packaging waste taking into account the separable packaging parts present in a certain waste stream, nor on their quantitative levels of (elemental) impurities. This paper therefore presents an unprecedented indepth analysis of the polymer and elemental composition, including $\mathrm{C}, \mathrm{H}, \mathrm{N}, \mathrm{S}, \mathrm{O}$, metals, and halogens, of commonly generated plastic packaging waste streams in European sorting facilities. Various analytical techniques are applied, including

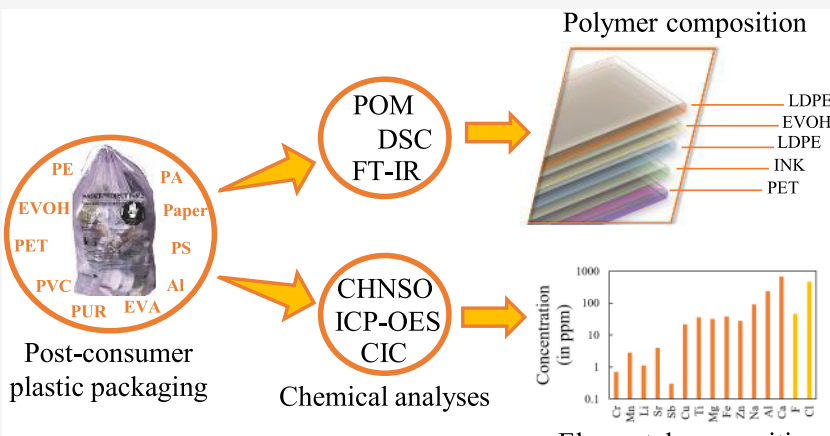

Elemental composition Fourier transform infrared (FTIR) spectroscopy, differential scanning calorimetry (DSC), polarized optical microscopy, ion chromatography, and inductively coupled plasma optical emission spectrometry (ICP-OES), on more than 100 different plastic packaging products, which are all separated into their different packaging subcomponents (e.g., a bottle into the bottle itself, the cap, and the label). Our results show that certain waste streams consist of mixtures of up to nine different polymers and contain various elements of the periodic table, in particular metals such as $\mathrm{Ca}, \mathrm{Al}, \mathrm{Na}, \mathrm{Zn}$, and $\mathrm{Fe}$ and halogens like $\mathrm{Cl}$ and F, occurring in concentrations between 1 and 3000 ppm. As discussed in the paper, both polymer and elemental impurities impede in many cases closed-loop recycling and require advanced pretreatment steps, increasing the overall recycling cost.

\section{INTRODUCTION}

Polymers possess a variety of properties that make them an attractive and indispensable material for various applications. Nevertheless, concerns are currently rising about plastics and in particular how to properly deal with them at the end of their life. ${ }^{1-4}$ This has led to more stringent legislation, for instance, set by the European Union, requiring that $50 \%$ of plastic packaging should be recycled by 2025 and $55 \%$ by $2030 .^{5}$ To date, mechanical recycling is the most commonly applied recycling technology, since this technology requires relatively little energy and resources. ${ }^{6}$ However, mechanical recycling faces various challenges such as thermal-mechanical degradation and immiscibility of different polymers, making the production of recyclates with a sufficient quality to be applied in high-end recycling routes (i.e., those with a destination other than mixed-polymer bulk applications like plant trays, compost bins, street or garden benches, etc.) out of heterogeneous waste streams very challenging. ${ }^{7,8}$ Another issue is the presence of certain components such as odorous constituents and inks, often containing metals and halogens and raising issues toward regulatory compliance due to the possible migration of such contaminants from the recycled material. This might be a potential risk for the health of consumers, especially in case of food contact materials (FCM). ${ }^{9,10}$

These drawbacks lead to a growing interest in chemical recycling technologies. In particular, thermochemical recycling technologies such as pyrolysis are stated to be promising alternatives for the mechanical recycling of plastic packaging waste. ${ }^{6,7,11}$ Via pyrolysis, polymers are converted into smaller molecules, which can subsequently be used to produce, among other things, new chemicals, fuels, and virgin plastics. ${ }^{7,12}$ It is stated that plastic waste streams with a high carbon content, such as PE (polyethylene), PP (polypropylene), and (E)PS

Received: June 4, 2020

Revised: August 25, 2020

Accepted: September 28, 2020

Published: September 28, 2020 


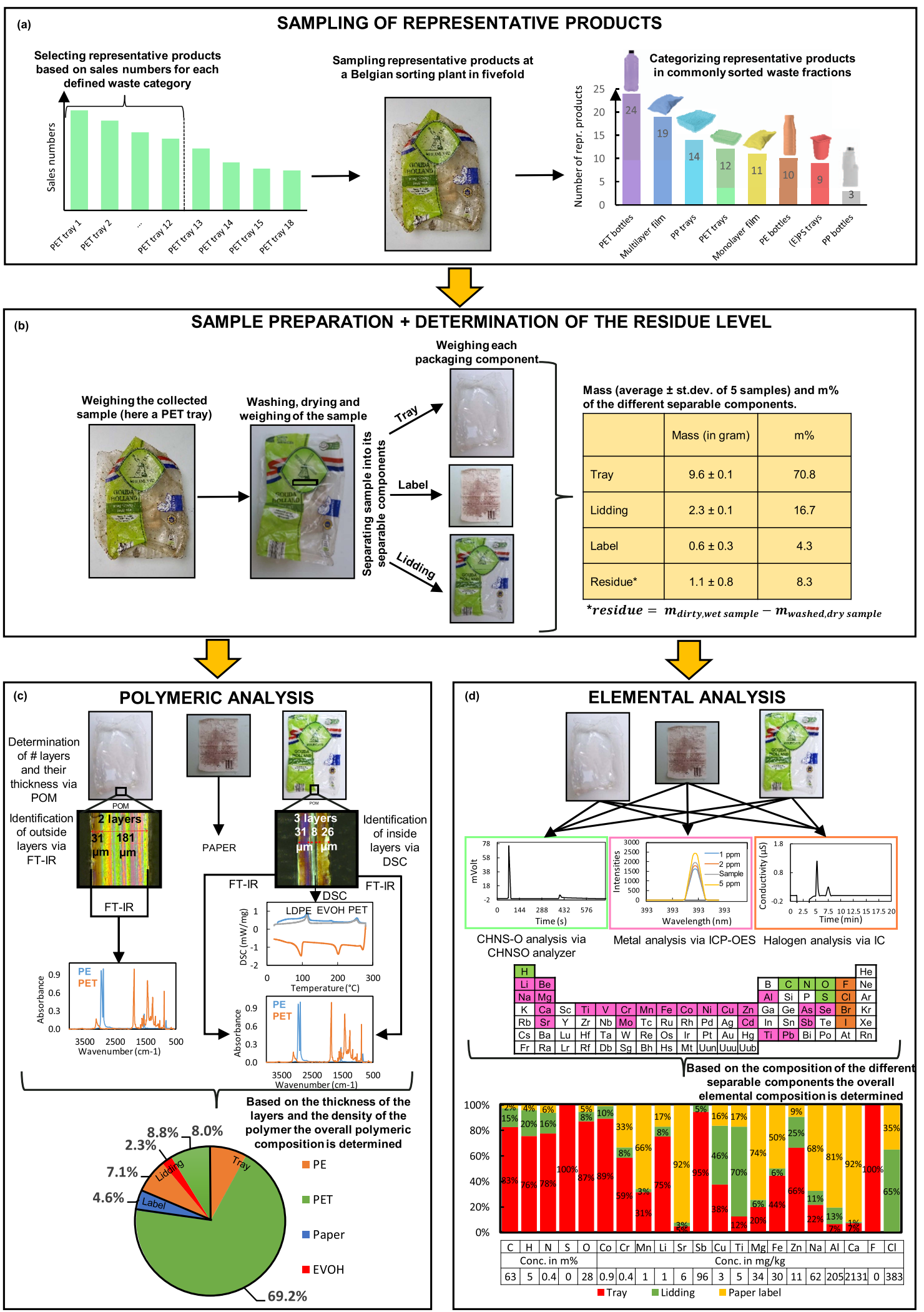

Figure 1. Schematic visualization of the applied methodology in this study: (A) 102 different packaging products are collected in fivefold at a Belgian waste sorting plant and subsequently divided into eight waste categories. (B) Each packaging is washed and dried to determine the residue level. Each product is separated into its separable components, resulting, in total, in 242 different plastic components, which are weighed individually to determine the mass percentage of the different separable parts. (C) Polymer composition of each separable part is determined via a combination of polarized optical microscopy (POM), attenuated total reflection-Fourier transform infrared spectroscopy (ATR-FTIR), and differential scanning calorimetry (DSC). (D) Elemental composition of each separable part is determined via a combination of CHNSO analysis, inductively coupled plasma optical emission spectrometry (ICP-OES), and combustion ion chromatography (CIC). 
((expanded) polystyrene) trays and bottles, are the preferred polymer feedstock for pyrolysis. ${ }^{7}$ However, these waste streams typically contain organic, polymeric, and paper contaminations, originating from, among other things, food residue, labels, lids, and caps, introducing unwanted heteroelements in the pyrolysis feedstock. Operational issues during pyrolysis caused by the presence of heteroelements are, for instance, corrosion of process equipment and reactors by halogens and sulfur, pollution of catalysts and coking in the reactor due to the presence of metals, and soot formation due to the presence of oxygen. ${ }^{7}$

Thus, it is clear that with the current industrially applied pretreatment technologies, comprising sorting, washing, and grinding technologies, different types of components remain present in post-consumer plastic packaging waste, which cause problems for both mechanical recycling and pyrolysis. More advanced decontamination techniques, such as ultrasonic and supercritical fluid extraction, might be more effective to remove certain impurities. However, it is hard to make such technologies scalable and cost-effective and they still require further research to be industrially applied. ${ }^{13}$ Ideally, optimizing such technologies starts with knowledge on the composition of the plastic waste. Yet, until today, only limited systematic data on the full composition of this type of waste are available. Here, we therefore present the synopsis of an in-depth analysis of the polymer and elemental (i.e., C, H, N, S, O, metals, and halogens) composition of different plastic packaging waste streams at the level of the separable components of each packaging type (e.g., a PET (poly(ethylene terephthalate)) bottle is separated into a PE cap, a PP label, and the PET bottle itself). This is in general not the case in previous studies since they are mostly limited to the determination of the "main" polymer of a packaging item (e.g., a PET bottle is categorized as $100 \%$ PET).$^{14,15}$ Although data are collected in Belgium, we expect to generate relevant information for many other European countries that have a separate collection system for household plastic packaging products such as PET, PE, and PP bottles, PS, PP, and PET trays, and plastic films. This is exemplified by various studies, which investigated the composition of plastic packaging waste in, among others, Denmark, Finland, the Netherlands, Spain, Austria, and Italy. ${ }^{14-19}$ Furthermore, in this study, we link the analytical results to common problems of mechanical recycling and pyrolysis to be able to elaborate more substantiated guidelines for improved waste management, including potential new and improved sorting and pretreatment steps, and design for recycling, which is relevant for governments and industry all over the world.

\section{MATERIALS AND METHODS}

Sampling of Waste Samples. The general methodology used in this study is schematically shown in Figure 1. We first defined the most common packaging types that are sorted in West-European sorting facilities, according to the so-called Deutsche Kunststoff Recycling (DKR) list that is applied in most European sorting facilities. ${ }^{14,20}$ We included the following waste streams: PET bottles, PET trays, PE bottles, PP bottles, PP trays, (E)PS trays, and plastic films. These product types are most commonly sorted in plastic sorting facilities and generated as output streams. ${ }^{20}$ For the latter category, we made an extra distinction between monolayer and multilayer films due to their difference in compositional complexity.
Within each packaging category, we selected best-selling products according to sales numbers of the biggest Belgian food retailer. ${ }^{21}$ For instance, certain water brands turned out to be among the best-selling PET bottles, where certain yogurt brands were among the best-selling PS trays. By sampling and analyzing the best-selling products, we aimed to cover a relevant fraction of plastic waste by the performed analyses. Moreover, the retailer's sales numbers were based on an entire year, whereas sampling without these numbers would limit the sample selection to products that were abundantly available at the moment of sampling. In effect, this sales-based approach helps us to limit the effects of seasonal variation in plastic packaging waste composition. Of each selected packaging product, we collected five replicates at the outlet of a Belgian waste sorting plant.

Based on the variability of the performed analyses, we consecutively evaluated for which waste category more samples needed to be analyzed to have a lower statistical variability across the products belonging to a certain waste category. As an indicative number for the variability of a waste stream, we used the standard error (SE) of the total metal content. As can be seen in Figure 2, the SE gradually decreased when more

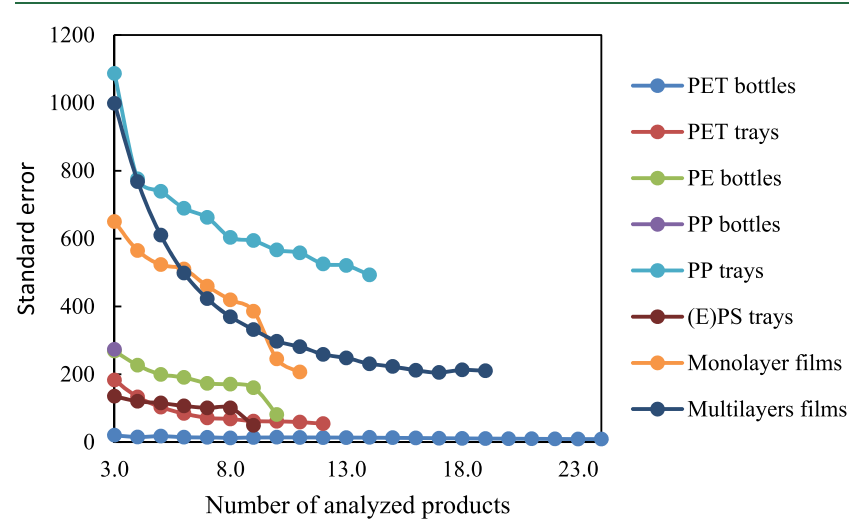

Figure 2. Standard error of the total metal concentration as a function of the number of analyzed packaging products per waste category.

samples of a certain packaging type were analyzed. Based on the SE value, the need to analyze more samples was evaluated. For instance, after analyzing metals in three multilayer films, we obtained an SE of 999, whereas metals in (E)PS trays had an SE of 115. This suggested the need to analyze more multilayer films compared to (E)PS trays to gain more representative data on the average composition of these waste streams and, as such, to increase the representativeness for the entire waste stream. For PET bottles, we applied this method per subcategory (i.e., PET clear, PET blue, PET green, PET opaque, and PET other), as created on the market after color sorting, explaining the larger number of analyzed PET samples. By the applied methodology, 102 products were selected and analyzed. The number of analyzed samples per waste category is given in Supporting Information Section 1.1. A descriptive list (without brand names) of the analyzed samples can be found in Table $\mathrm{S} 1$.

Quantification of the Mass Fractions of the Packaging Subcomponents and the Residue Fractions. The degree of contamination by dirt and moisture, together called "the residue level", was quantified by weighing the samples before and after manually washing with distilled water at 60 ${ }^{\circ} \mathrm{C}$. The washing efficiency was visually evaluated, and washing 


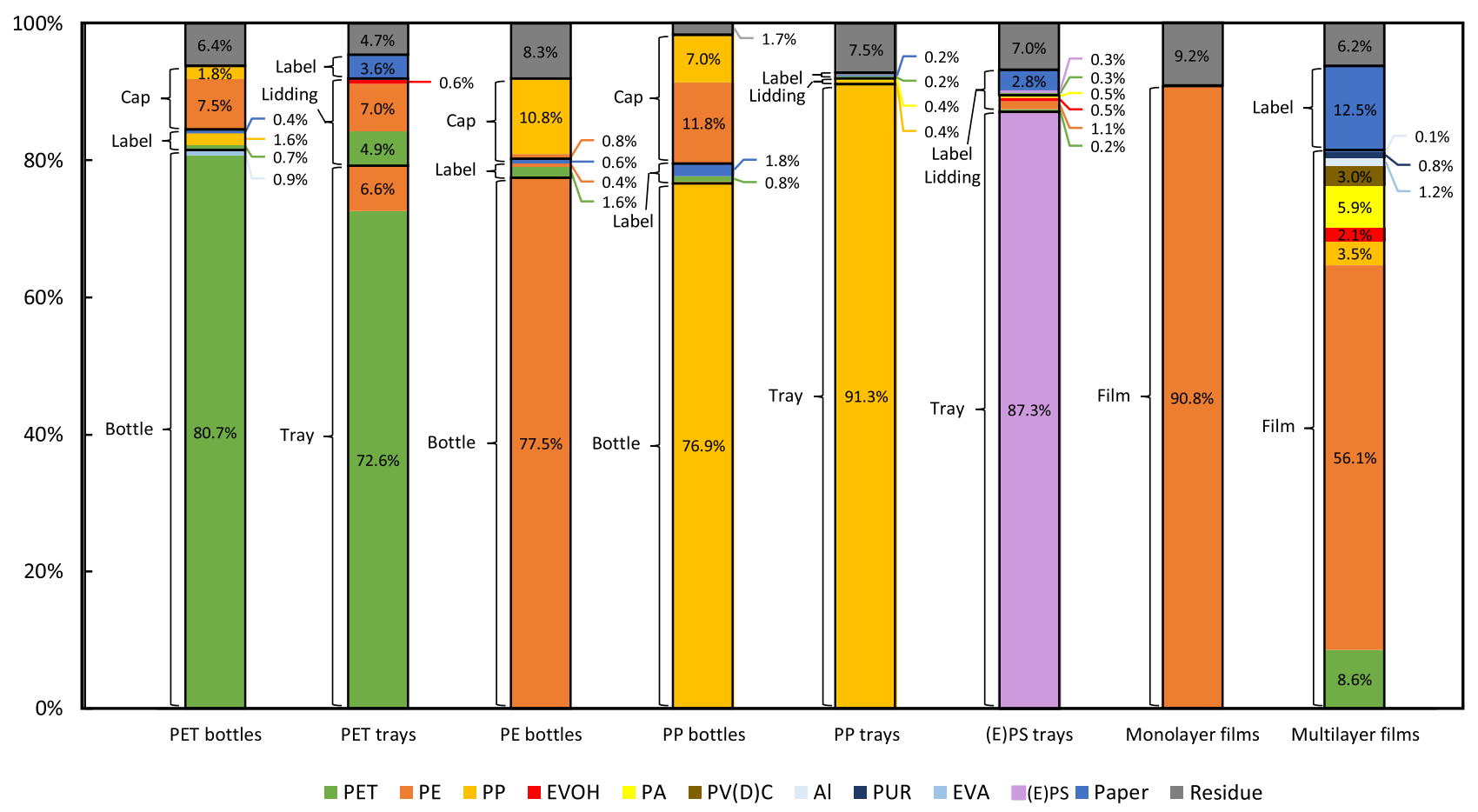

Figure 3. Polymer composition and residue level of the different waste categories. The bars are divided into separable components of each specific waste category (e.g., into a bottle, label, cap, and residue fraction for the PET bottle stream). The polymer composition is visualized by different colors per separable component (e.g., PET is always shown in green) together with the corresponding mass percentages.

was repeated until no dirt was visible anymore. The number of washing cycles varied between 1 and 4, depending on various factors such as the degree and type of contamination and the shape of the packaging product. For instance, in some cases, PET trays were strongly compressed, and accordingly, water could not thoroughly reach the entire surface of the tray and, as such, more washing cycles were required. The same remark is valid for packaging products that contain a high organic residue fraction, originating, for instance, from the content of the packaging. Thereafter, the products were dried for $4 \pm 1 \mathrm{~h}$ at atmospheric pressure at $60{ }^{\circ} \mathrm{C}$ until constant weight was achieved.

The separable packaging subcomponents (i.e., packaging components that can be physically separated from the main packaging component) were manually separated from the main packaging part (i.e., bottles, trays, and films). Subsequently, paper labels present on any of the separated packaging subcomponents were removed by means of a hot water wash at $80{ }^{\circ} \mathrm{C}$. If necessary, a cleaning tool was used to apply friction (in case hot water was not able to dissolve the adhesive between layers). The efficiency was again visually evaluated. The calculations to obtain the average residue and paper content per waste stream are explained in Supporting Information Section 1.2.

Quantification of the Polymer Composition. As a first step, ATR-FTIR was applied on both sides of each packaging item. ATR-FTIR analyses were performed on a Bruker Tensor 27 FTIR spectrometer. Each analysis consisted of 32 scans with a resolution of $4 \mathrm{~cm}^{-1}$. The wavenumber region ranged from 400 to $4000 \mathrm{~cm}^{-1}$. If the ATR-FTIR analysis showed that both sides of the packaging item consisted of the same polymer and the particular packaging item (i.e., bottle, cap, label) had a high probability of consisting of one layer based on expert judgment during the analysis, the packaging item was categorized as monomaterial, consisting of $100 \%$ of the identified polymer.

If the ATR-FTIR analysis showed that both sides of the packaging item did not consist of the same polymer or if the packaging item had a high probability of consisting of more than 1 polymer (i.e., trays and films), further characterization was performed. For those packaging components, the number of layers and their thickness were determined via POM, according to a method adopted from Simoneau et al. ${ }^{22}$ Besides, also a first indication on the polymer composition of the multilayer was given via POM, as explained in Supporting Information Section 1.3. Prior to POM analysis, the samples were first clamped between polystyrene plates to mediate sectioning. Thin sections of film, ranging from 5 to $15 \mu \mathrm{m}$, were prepared by the use of sectioning tape and a Leica RM 2245 microtome. The sections were thereafter placed on a microscope slide, embedded in Canada balsam, and conditioned for $24 \mathrm{~h}$ under a bench press. Subsequently, POM analysis was performed on a Keyence VHX-500F microscope.

If the POM analysis showed that a packaging item consisted of more than two layers, the multimaterial packaging item was further characterized by means of DSC. DSC analyses were conducted under $\mathrm{N}_{2}$ with a NETZSCH Polyma DSC 214, starting at a temperature of $20^{\circ} \mathrm{C}$ and ending at a temperature of $300{ }^{\circ} \mathrm{C}$ with a heating rate of $10{ }^{\circ} \mathrm{C} \mathrm{min}{ }^{-1}$. The applied nitrogen flow was $20 \mathrm{~mL} \mathrm{~min}{ }^{-1}$. Aluminum crucibles were used ( $\sim 8 \mathrm{mg}$ sample weight), and baseline correction using an empty crucible was performed before every measurement. Samples were evaluated by the first heating run and confirmed by the second heating run. Examples of POM images, DSC spectra, and ATR-FTIR spectra of two multilayered materials are shown in Supporting Information Figures S3 and S4.

Based on the theoretical density and the thickness of a polymer, the polymer composition of the multilayer structure 
was calculated (a hypothetical example is shown in Table S2). Based on the polymer composition and the mass fraction of each packaging item, the polymer composition per packaging product was calculated. Consequently, based on the polymer composition per product, the average polymer composition per waste stream was calculated.

Quantification of the Elemental Composition. Prior to the elemental analyses, all replicates of a certain packaging item were together reduced to flakes on a Piovan-type RSP15/30 shredder with a sieve diameter of $8 \mathrm{~mm}$. Of each homogenized packaging item, the $\mathrm{C}, \mathrm{H}, \mathrm{N}, \mathrm{S}$, and $\mathrm{O}$ contents, the metal concentration, and the halogen concentration were determined by means of an elemental analyzer, ICP-OES, and CIC, respectively.

CHNSO analyses were performed on a PerkinElmer 2400 Series II CHNSO Elemental Analyzer at a combustion temperature of $975{ }^{\circ} \mathrm{C}$ using pure oxygen and helium as carrier gases.

ICP-OES analyses were performed on a Thermo Scientific iCAP 7200 model, equipped with Qtegra Software and a CETAC AXP 560 autosampler. The operational parameters used during ICP-OES analyses are shown in Table S3. Table S4 shows the LOD, LOQ the viewing mode (axial or radial), and the emission lines used to analyze each element. Calibration standards (ranging from 0.001 to $20 \mathrm{ppm}$ ) were prepared from a XVI Certipur multielement standard solution ( $100 \mathrm{mg} \mathrm{L}^{-1}$ in $10 \% \mathrm{HNO}_{3}$ ). Prior to ICP-OES analysis, the samples were thermally destructed by a muffle oven at $550{ }^{\circ} \mathrm{C}$ for $12 \mathrm{~h}$. The remaining ash was dissolved in $5.0 \mathrm{~mL}$ of $\mathrm{HNO}_{3}$ (70\%, Sigma-Aldrich) and diluted with double-distilled water until a $\mathrm{HNO}_{3}$ concentration of $10 \%$ was achieved. Thereafter, the samples were filtered using a syringe filter $(0.45 \mu \mathrm{m}$ syringe filter, PP filter media, CHROMAFIL).

The chlorine, fluorine, bromine, and iodine concentrations were determined by CIC measurements performed on a Thermo Scientific Dionex ICS-3000 model, equipped with an ICS-3000 conductivity detector (operated at $250 \mu \mathrm{L}$ sample loop volume, using $10.0 \mathrm{mM}$ carbonate $/ 5 \mathrm{mM}$ bicarbonate eluent at $1.0 \mathrm{~mL} \mathrm{~min}^{-1}$ ) and a Thermo Scientific Dionex ASAP autosampler. Prior to analysis, the samples were pyrolyzed in an oxidizing atmosphere according to the method described in CMA/2/II/B.2, using ca. $1 \mathrm{~g}$ of sample. The resultant vapors are absorbed in an aqueous solution and subsequently introduced into the IC system for analysis according to the CMA/2/I/C.3 method.

\section{RESULTS}

Figure 3 presents the average polymer composition of the analyzed plastic packaging products, together with the residue and paper content. To calculate the average polymer composition, both monolayer and multilayer materials are taken into account. Some types of packaging items consist mostly, or even entirely, of monolayer materials (e.g., the caps present on bottles). In such a case, the division into different polymers within a certain packaging component is caused by the fact that the specific separable packaging item can be made out of different polymers on different products (e.g., a PP bottle with a PE cap versus a PP bottle with a PP cap). Other types of packaging items mainly consist of multilayer materials (e.g., lids present on a PET tray). In this case, the data in Figure 3 represent the average composition of the multilayer material. For instance, the lids of PET trays consist on average of $39.2 \% \mathrm{PET}, 58.3 \% \mathrm{PE}$, and $2.5 \% \mathrm{EVOH}$ (ethylene vinyl alcohol). The share of multilayer materials per packaging category and per packaging item are shown in Supporting Information Table S5 to be able to evaluate the data shown in Figure 3 more in depth.

An indication of the statistical dispersion of the results can be found in Supporting Information Figure S1 and Tables S6S13, showing that multilayer films have by far the most heterogeneous polymer composition with an average effective main polymer composition of $56.1 \pm 35.0 \mathrm{~m} \%$ (resulting in a relative standard deviation (RSD) of $62.4 \%$ ), followed by (E)PS trays having an average effective main polymer composition of $87.3 \pm 19.1 \mathrm{~m} \%$ (RSD of $21.9 \%$ ). PET bottles, on the other hand, have a relatively homogeneous composition with a main polymer composition of $80.7 \pm 9.8 \mathrm{~m} \%$ (RSD of $12.1 \%)$

In reality, polymer contamination due to mis-sorting (e.g., a PE bottle ending up in the PET bottle stream) will influence the composition of a waste stream. However, as the amount of sorting errors depends on various factors such as configuration of the sorting line, composition of the input, and load on the conveyor belt, we did not take this into account in this study. This allowed us to identify recycling problems inherently caused by the type of packaging and their use. Besides, by not taking into account sorting or pretreatment steps, the obtained data can be used by both plastic waste processing companies and plastic packaging producers and can initiate a discussion between both sectors to better align the design of a packaging and its recyclability.

Our results show that the majority of waste streams consist of a mix of different polymers, even if plastic sorting would be $100 \%$ efficient. For instance, PET bottles are contaminated by a residue fraction, caps, and labels. The bottles themselves contain, in some cases, a second polymer such as ethylene vinyl acetate (EVA), which can be used for its good sealing properties.

PET trays have a more complex composition than PET bottles. Besides paper labels and a residue fraction (on average 3.6 and $4.7 \mathrm{~m} \%$, respectively), the trays and lids generally consist of two or three layers of different polymer types, each with their specific function, improving the overall performance of the packaging. PET is mainly used at the outside of a tray or lid for its water and gas barrier properties and its mechanical strength, while PE is used at the inside for its attractive sealing properties and because it is a relatively inexpensive material.' An EVOH layer can optionally be added to the lids for its superior oxygen barrier properties, which is generally required for food packaging. ${ }^{7}$

PE and PP bottles are both usually monopolymer products, although caps and labels inherently contaminate these streams. The products categorized in the PE and PP bottle streams contain on average $10.8 \mathrm{~m} \% \mathrm{PP}$ caps and $11.8 \mathrm{~m} \%$ PE caps, respectively. Labels can be made of $\mathrm{PE}$, paper, or PET. Both packaging types also contain a residue fraction, averaging $8.3 \mathrm{~m}$ $\%$ in case of PE bottles and $1.7 \mathrm{~m} \%$ in case of PP bottles. This significant difference might be explained by the specific surface area of both packaging types. PP bottles, which are mainly used as laundry detergent bottles, have in general a higher capacity compared to PE bottles such as shampoo bottles. Consequently, its specific surface area (expressed as $\mathrm{m}^{2} \mathrm{~kg}^{-1}$ ), on which residual contamination from the packaging content might be attached after disposal, is lower than the one of PE bottles. Therefore, the residue content of PP bottles has a lower share in the total weight compared to $\mathrm{PE}$ bottles. 
(A) PET bottles

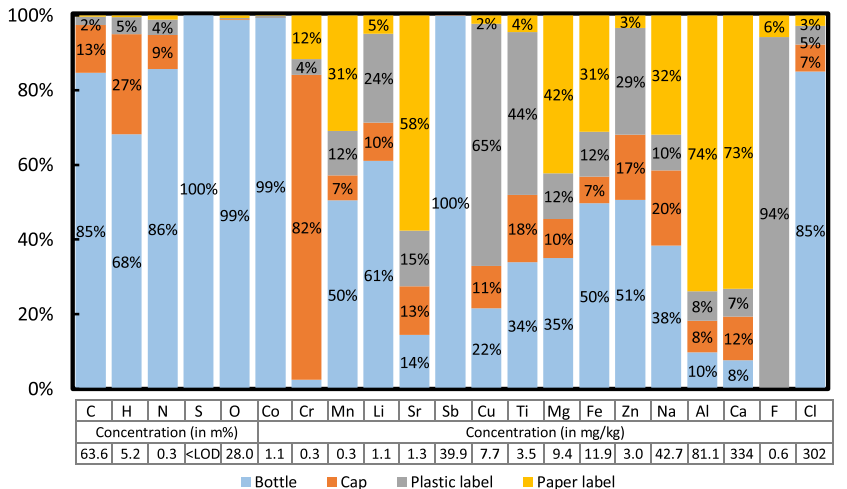

(C) PE bottles

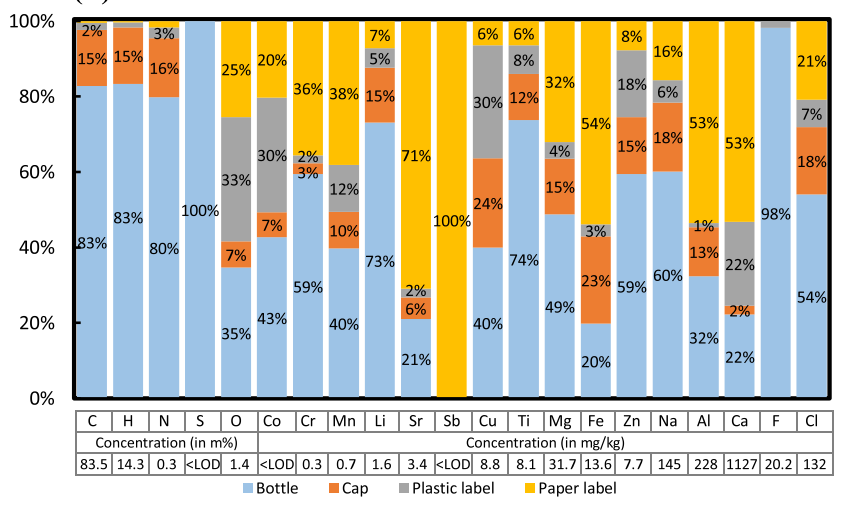

(E) PP trays

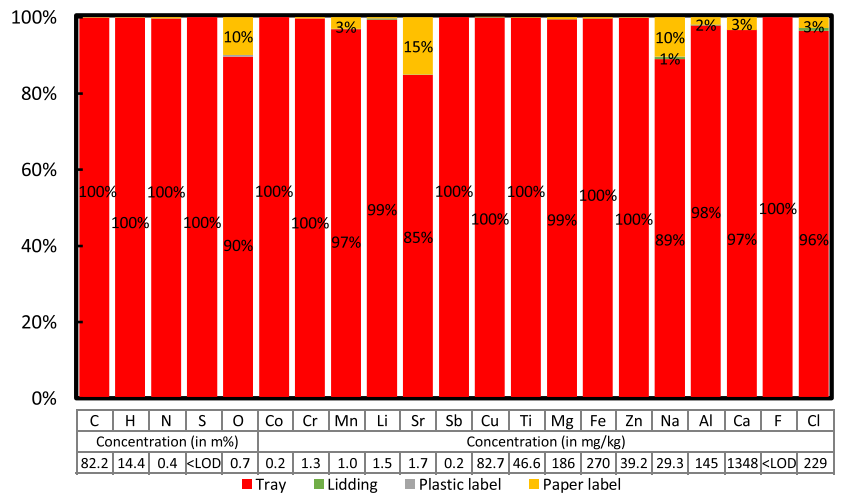

(G) monolayer films

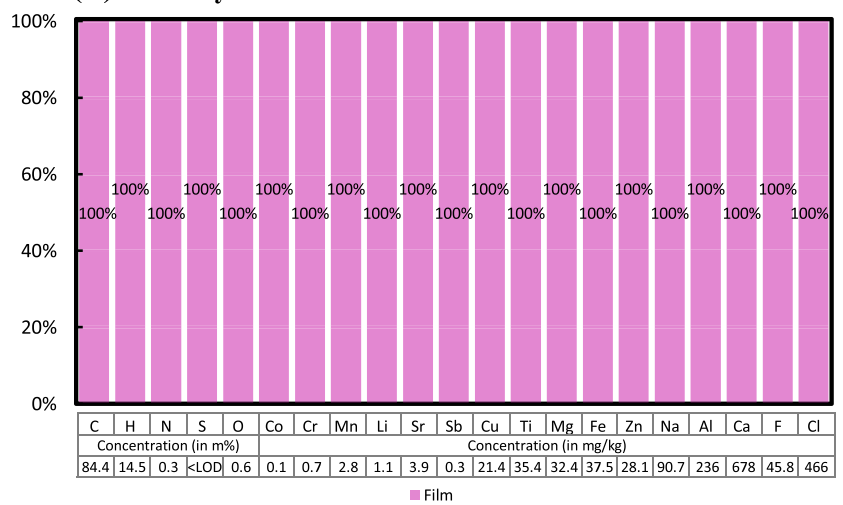

(B) PET trays

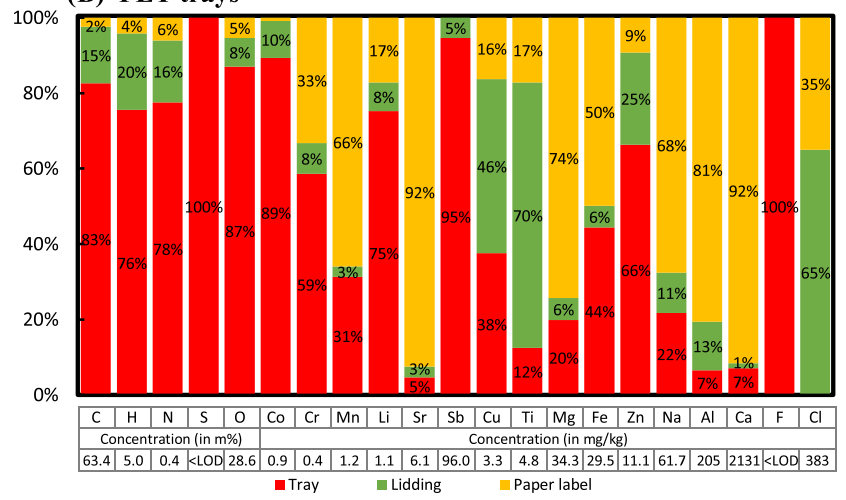

(D) PP bottles

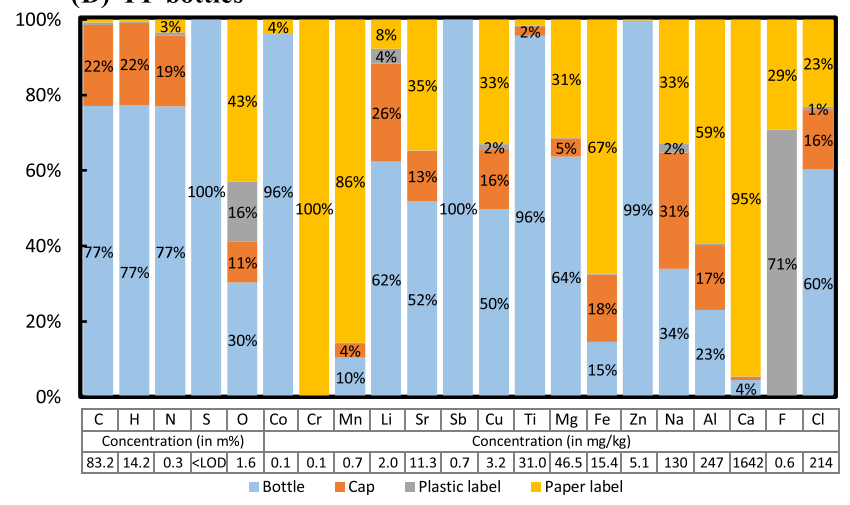

(F) (E)PS trays

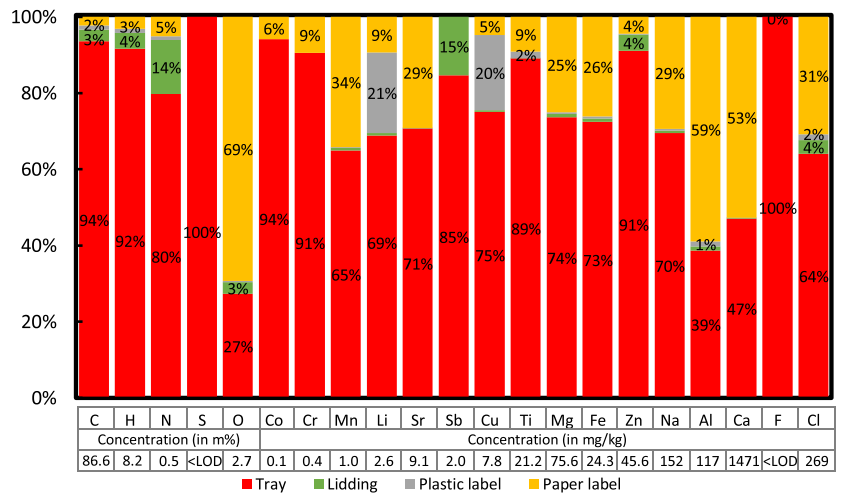

(H) multilayer films

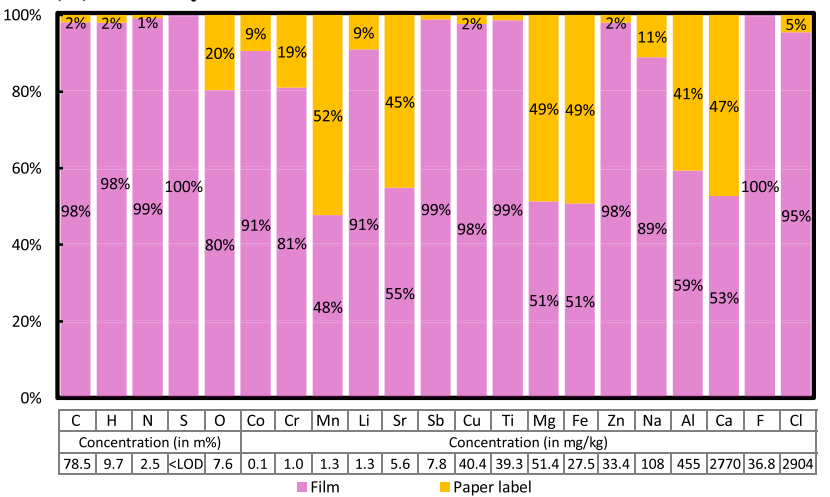

Figure 4. Average overall C, H, N, S, O, metal, and halogen contents of the entire waste stream (in $\mathrm{m} \%$ for $\mathrm{C}, \mathrm{H}, \mathrm{N}, \mathrm{S}$, and $\mathrm{O}$ and in $\mathrm{mg} \mathrm{kg}{ }^{-1}$ for metals and halogens) and contributions (in \%) of the different packaging subcomponents (visualized by different colors: blue box bottles, red box trays, orange caps, yellow box paper labels, gray box plastic labels, green box lids, and pink box films) per waste stream.

However, since the sample size was rather limited, this hypothesis should be confirmed by further research.
PP and (E)PS trays are slightly contaminated by debris and moisture, lids, and labels. Lids on PP trays mostly consist of 
PP, while the labels are usually made of paper. Lids on (E)PS trays consist of various polymer types such as PET, PE, EVOH, and PA. Labels are in general made of PET, PS, or paper.

Depending on the quality requirements of a packaging, multilayer films could be more suitable for certain applications compared to monolayer films (e.g., for food preservation and moisture-sensitive products). A PET layer typically offers a good water and gas barrier to multilayer films, while PE and PP are mainly used for their preferred sealing properties. PE is a frost-resistant polymer and is therefore a suitable polymer for frozen foods. If more advanced properties are desired, EVOH can be used as an oxygen barrier (e.g., for meat and fish products), PA can be used to give rigidity to the packaging or to increase puncture resistance (e.g., for cheese packaging), or poly(vinyl chloride) (PVC) or poly(vinylidene chloride) (PVDC) can be used as an odor and gas barrier (e.g., for smoked food). ${ }^{23,24}$ If even more barrier is desired, a packaging may incorporate a metallized layer (e.g., in chips packaging). Next to the broad range of polymers, multilayer films also contain paper labels and a residue fraction. In contrast to the varied polymer composition of multilayer films, monolayer films are generally only made of $\mathrm{PE}$, resulting in a relatively pure monopolymer stream that is only slightly contaminated by a residue fraction. However, it should be noted that monolayer films are currently difficult to sort with high purity from a mixed film fraction.

It is commonly accepted that a mixture of different polymers will in most cases result in an incompatible blend due to the high interfacial activity between the polymers. ${ }^{25-27}$ For instance, Huysman et al. categorized polymer blends into four compatibility classes based on interfacial tension: (1) perfectly compatible polymers (e.g., LDPE/LLDPE), (2) reasonably compatible polymers (e.g., $\mathrm{PE} / \mathrm{PP}),(3)$ incompatible polymers (e.g., PE/PET), and (4) grossly incompatible polymers (e.g., PE/PA (polyamide)). ${ }^{28}$ Since most waste categories are already complex in terms of polymer composition, without including cross-contamination originating from other waste categories, and have different levels of polymer purity, advanced sorting of packaging products is in most cases recommended prior to mechanical recycling to reduce such compatibility issues and the accompanying deterioration of mechanical properties. For instance, mixing PET bottles and PET trays would contaminate the PET fraction of the PET bottles with inseparable PE originating from PET trays. As PET and PE (and PP) are incompatible polymers, blending these polymers would yield immiscible blends. ${ }^{7}$

Moreover, even for relative reasonably compatible polymers, such as PE and PP, previous studies have shown that mixing these polymers still might have a negative influence on the mechanical properties of the recyclates. Van Belle et al., for instance, showed that phase separation might occur when different types of polyolefins are processed as blends, despite their basic structural similarities. It was stated that the two high-crystalline polymers HDPE (high-density polyethylene) and PP undergo shear yielding and display clear neck formation and that blending PP and HDPE leads to brittle structures, even at a low concentration, which, for instance, can be caused by polymer contamination originating from caps. ${ }^{29}$ Mixing PP bottles and PP trays might thus induce PE contamination from the caps of the PP bottles into the PP tray stream, depending on the efficiency of separation of PE and PP. Without further purification and sorting steps, the polymer contamination levels that are present in most packaging products would thus result in inferior properties of the recyclates, if blended as such.

Another observation based on the results presented in Figure 3 is the importance of separating monolayer and multilayer films as they have an enormous difference in terms of polymer complexity. However, as it is, from a technical point of view, very challenging to obtain a $100 \%$ efficient separation during sorting, additional measures might be suggested, such as source separation of monolayer and multilayer films by consumers to facilitate plastic packaging sorting processes.

An additional issue related to mechanical recycling is the presence of unwanted accumulating substances such as certain metals, which can cause problems for recycled plastics, for instance, to meet the legislative migration thresholds of certain metals for FCM. ${ }^{9,30}$ Figure 4 shows indeed that plastic waste contains various elements of the periodic table, such as certain metals and halogens. As it is unknown if and how much metals and halogens could potentially migrate from plastics, a direct comparison of the results from this study to legal migration limits is not possible yet. However, for certain metals analyzed in this study, maximum allowable concentrations are defined for applications in electrical and electronic equipment (i.e., $\mathrm{Pb}$ $1000 \mathrm{ppm}, \mathrm{Cr}^{6+} 1000 \mathrm{ppm}$, and $\mathrm{Cd} 100 \mathrm{ppm}$ ), yet these values are never exceeded in the plastic packaging products analyzed in this study. ${ }^{31}$

An indication of the statistical dispersion of the elemental analyses can be found in Supporting Information Figure S2 and Table S14, showing that for certain waste streams, a relatively high variability can be observed across the analyzed packaging products. Figure S2 shows that PP trays, for instance, have a $25 \%$ percentile value of $20.1 \mathrm{ppm}$ and a $75 \%$ percentile value of $198 \mathrm{ppm}$ for metals with food contact material (FCM) regulation, yet the average value is $395 \mathrm{ppm}$, which is significantly higher than the $75 \%$ percentile value. This shows that in this case, the average value is strongly influenced by some outliers. This can be explained by the different nature of the analyzed samples within this waste category. The PP tray stream indeed consists of a combination of FCM products such as meat trays and non-FCM products such as flower pots, which strongly vary in terms of their metal content. Waste categories with a higher proportion of FCM have, in general, a relatively low variation of the FCM regulated metal content (e.g., the analyzed PET trays, which all served as food packaging, have a $25 \%$ percentile value of 26.1 $\mathrm{ppm}$, an average of $47.1 \mathrm{ppm}$, and a $75 \%$ percentile value of $78.3 \mathrm{ppm}$ ). For metals without FCM regulation, the highest variability is observed within the multilayer film waste stream, having a $25 \%$ percentile value of $320.0 \mathrm{ppm}$, an average value of $3438 \mathrm{ppm}$, and a $75 \%$ percentile value of $2196 \mathrm{ppm}$. This shows again that outliers strongly enhance the average value. The same trend is observed for the halogen content of multilayers with a $25 \%$ percentile value of $510.6 \mathrm{ppm}$, an average of $2941 \mathrm{ppm}$, and a $75 \%$ percentile value of $1038 \mathrm{ppm}$. The variability of the results within this waste stream can be explained by the huge compositional differences across multilayers, each containing different polymer types, additives, inks, etc. PP bottles, on the other hand, which are more homogeneous in terms of polymer composition, also have a lower elemental variability (i.e., a $25 \%$ percentile value of 184 $\mathrm{ppm}$, an average of $215 \mathrm{ppm}$, and a $75 \%$ percentile value of 248 ppm for the halogen content). 

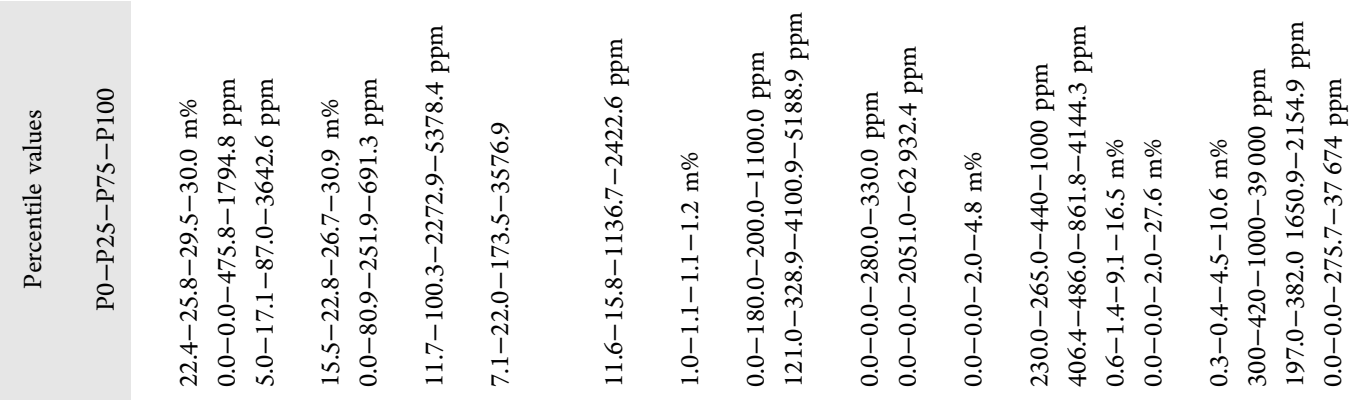

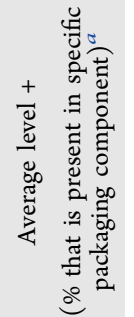

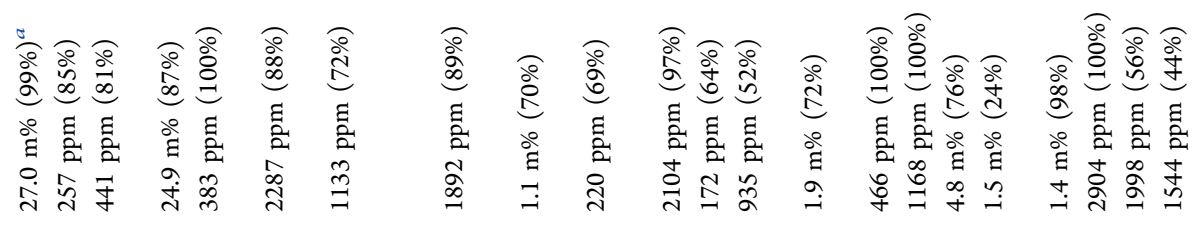

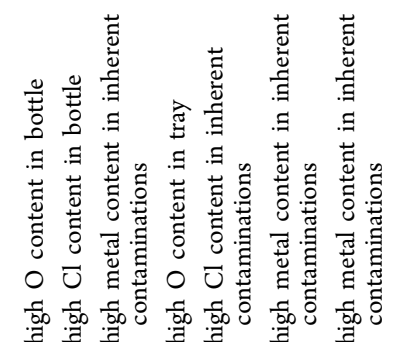

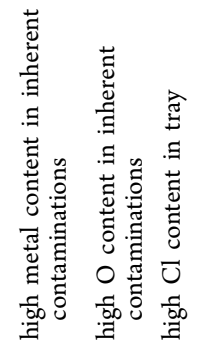

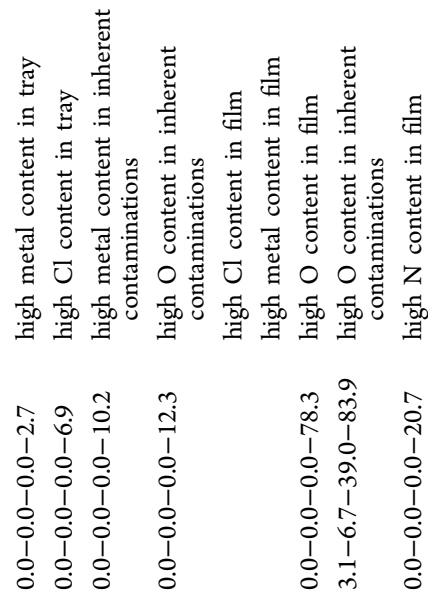

责

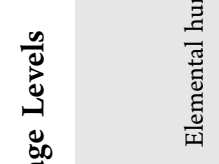

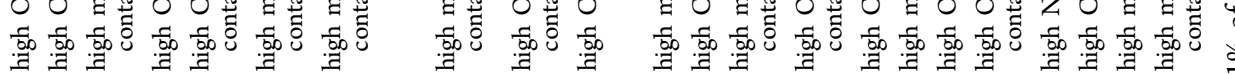

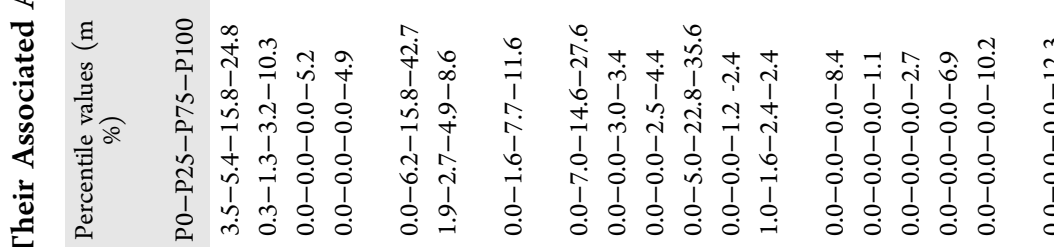

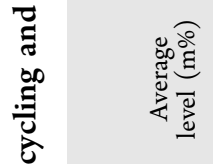

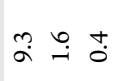

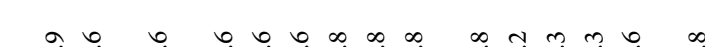

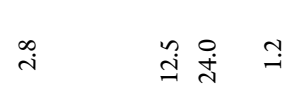
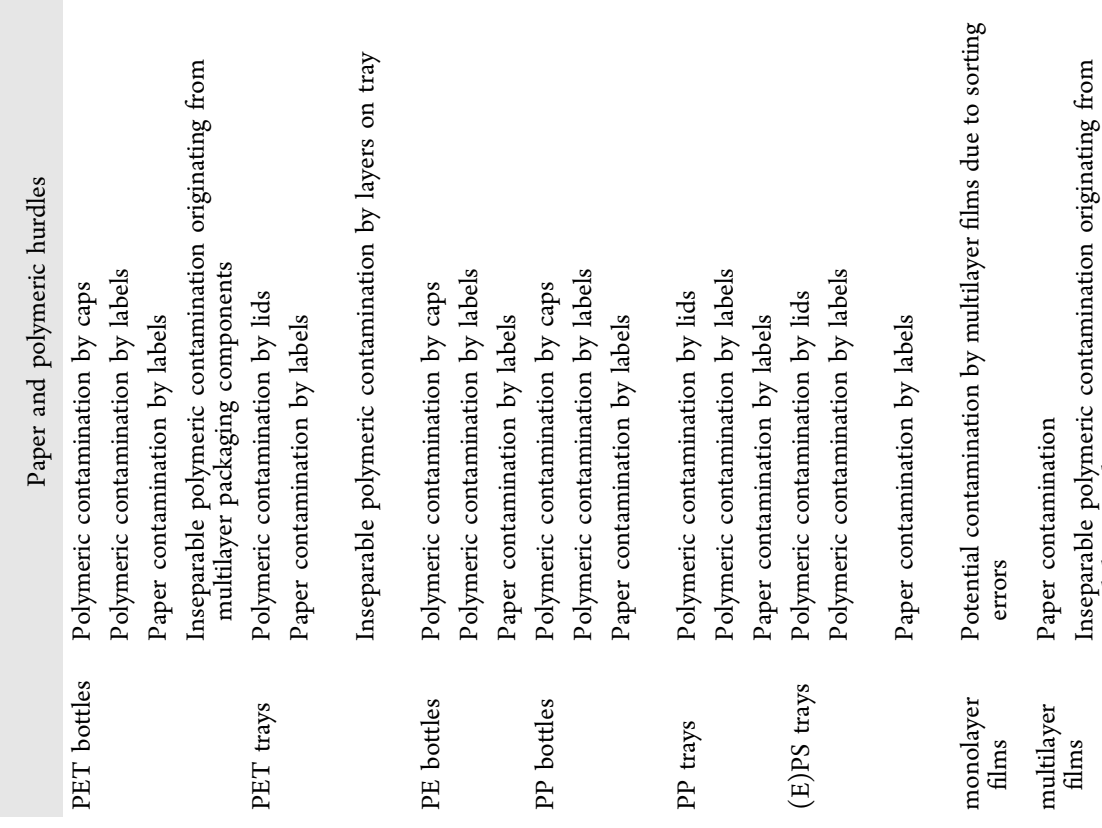

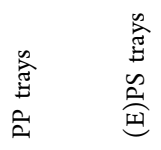


Products formed by pyrolysis are subjected to strict elemental requirements to be used as a replacement for fossil-based feedstock such as naphtha or fuels. For instance, a high sulfur content in the pyrolyzate, which is the liquid fraction produced by pyrolysis, can indeed limit further fuellike applications (e.g., the automotive industry allows a maximum sulfur content of $10 \mathrm{ppm}) .^{7,32}$ For biomass-based pyrolysis feedstock, one aims to reduce the oxygen content to less than $0.1 \mathrm{~m} \%{ }^{33}$ Pyrolysis of an oxygen-rich polymer feedstock can indeed result in the production of certain acids (e.g., benzoic acid and terephthalic acid), which can affect the reactor due to their corrosive nature, contaminate the pyrolysis output, and cause clogging of piping and heat exchangers. ${ }^{34,35}$ The latter necessitates frequent maintenance of the downstream equipment, resulting in a lower plant reliability. ${ }^{36}$ Oxygen present in the pyrolysis oil also lowers the heating value, causes thermal instability, and results in elevated soot levels, requiring energy-intensive gas cleaning and enhancing the risk of periodic plant shutdowns. ${ }^{37-40}$ These oxygeninduced issues imply that oxygen-rich packaging types such as PET trays, PET bottles, and multilayer films are more challenging to be pyrolyzed and can contaminate the polyolefin-based waste streams and, as such, increase the costs associated with expensive pretreatment steps.

Another challenge is posed by the presence of chlorine. As $\mathrm{HCl}$ is highly corrosive, it can damage process and reactor equipment. ${ }^{41}$ In addition, a high chlorine content in the pyrolysis output prevents its use as a fuel or petrochemical feedstock. A typically used specification for the use of the liquid fraction indicates that this fraction may not exceed a chlorine concentration of 10 ppm. ${ }^{7}$ As can be seen in Figure 4, each waste stream has a relatively high average chlorine concentration (between 132 and 2904 ppm), and thus precautions such as using corrosion-resistant materials, extensive polymer sorting, and dehalogenation are suggested to apply pyrolysis. Another option is to remove chlorine, for instance, by chemical washing or devolatilization or by actions related to packaging design. ${ }^{42}$

Plastic waste streams that contain metals in high concentrations are also undesired as pyrolysis feedstock, since metals can cause deposition and coking in the reactor, pollute the formed end products, and harm process equipment such as flow controllers and pumps. ${ }^{43}$ High metal concentrations also decrease the oil yield and increase the char/coke and noncondensable gas yield during pyrolysis. ${ }^{41,44}$ Additionally, metals can cause fouling of catalysts by blocking their pores, resulting in a permanent deactivation of a large number of active sites. ${ }^{7}$ The results presented in Figure 4 show that metals can originate from separable packaging components such as paper labels, lids, and caps. However, some packaging types also contain polymers with a relatively high intrinsic metal concentration. Reducing the metal concentration in such packaging items is more challenging. Due to the different origin of metals in different types of packaging, finding an optimal balance between waste stream selection, "cleaner" packaging design, level and cost of waste sorting, pretreatment of the waste feedstock, reactor design, process conditions, treatment of the pyrolyzate before cracking, and downstream processing of the cracked products is needed to minimize the process cost and maximize the product quality.

\section{DISCUSSION}

Recycling rates in Belgium, and in many other countries, are currently typically calculated by dividing the amount of plastic packaging "collected for recycling" (including dirt, moisture, food residue, and other materials) by the amount of plastic packaging "placed on the market" (in a clean and dry state). ${ }^{45}$ Consequently, recycling rates are currently systematically overestimated. This is addressed in this study, in which we determined the average residue fraction present on the analyzed waste streams, which varied between $1.7 \mathrm{~m} \%$ for the PP bottle stream and $9.2 \mathrm{~m} \%$ for the monolayer film stream.

In this study, we have also performed a detailed analysis of the polymer and elemental composition of different types of plastic packaging waste in Belgium. We analyzed the most relevant samples based on sales numbers and consecutively looked at the variation of the elemental composition per waste category to increase the representativeness for each included category, within the time and resource limitations of the study. However, it should be noted that this methodology resulted in relatively small sample sizes for the most homogeneous packaging categories. A follow-up study could focus on one or two waste categories and sample more items within these categories to confirm our findings and to study the variability on a larger number of samples. Moreover, the behavior of different types of household packaging products in waste sorting facilities might be subjected to further research to confirm the assumption that the best-selling products are also most abundant in the sorted waste streams.

The production chain of plastic packaging is usually globalized, including small and medium-sized enterprises (SMEs), as well as large multinationals, and comprises raw material producers, converters, packers/fillers, and brand owners, among others. So, there are, to a certain extent, similarities in terms of plastic packaging composition across different European and non-European countries. The typical thermoplastic polymers used in packaging on the Belgian market, namely, PET, PE, PP, and PS, are also the most important polymers in other European countries. ${ }^{14-19}$ Moreover, also in countries such as the United States and South Korea, these polymers are typically applied for household packaging products. ${ }^{46,47}$ Due to these similarities in terms of composition of packaging products across different countries and the modular character of the presented data, the results of this paper can potentially be used as starting point in other regions to set up similar analytical campaigns or, with careful interpretation, to feed discussions on implementation or adaptation of waste management systems. Yet, data from other countries across the world should also be gathered to actually be able to assess true compositional variability across different countries.

Table 1 identifies the polymer and elemental hurdles that need to be tackled toward closed-loop recycling, for instance, by applying new or improved waste-collecting steps, sorting steps, or pretreatment steps. Table 1 also contains percentile values to indicate the variation of the contamination levels. Our study demonstrated that almost all waste categories contain different types of polymers, even if all packaging would be $100 \%$ correctly sorted, and that polymer contamination occurs in various levels, depending on the heterogeneity of packaging products ending up in the concerning waste stream. For instance, the relatively homogeneous PET bottle stream 
contains on average $11.8 \mathrm{~m} \%$ non-PET polymers, whereas the heterogeneous multilayer waste stream contains on average $25.2 \mathrm{~m} \%$ non-PE polymers. These results are in accordance with previous studies, which already showed the enormous complexity of plastic packaging waste. ${ }^{19,48-50}$ In many cases, polymer complexity can be reduced by applying sorting and pretreatment steps. However, each separation process induces extra capital expenditures (CAPEX) and operating expenditures (OPEX), which may not be preferable in plastic recycling, given the associated typically low profit margins. Moreover, there are packaging types that contain polymers that are not easily separable by such physical/mechanical separation processes. According to our analysis, these account for around $0.9 \mathrm{~m} \%$ in PET bottles, $6.6 \mathrm{~m} \%$ in PET trays, and $24.0 \mathrm{~m} \%$ in multilayer films. These polymer contaminations might need more "chemical" treatments such as delamination, selective dissolution, or different types of depolymerization, which are hard to make profitable at this moment, among others, due to the complexity of the input stream.

Furthermore, these chemical techniques might have more problems with contaminations at elemental level such as metals and halogens. ${ }^{7}$ The total metal concentrations of each waste stream analyzed in this study varied between $537 \mathrm{ppm}$ for PET bottles and $3542 \mathrm{ppm}$ for multilayer films. The total halogen concentration varied between $152 \mathrm{ppm}$ for PE bottles and 2941 ppm, again, for multilayer films. Based on the data obtained in this study, it is clear that certain pretreatment steps should be able to significantly decrease the degree of various elemental contaminations to make certain waste streams more suitable for chemical recycling techniques. For instance, removal of paper labels could significantly reduce the metal concentration in certain waste streams. Another possibility to reduce the metal level in some packaging products is by deinking them as many inks contain certain metals. ${ }^{30}$ Yet, to date, no industrial full-scale deinking plant exists, emphasizing the need for more research in this research area. ${ }^{51}$

It is increasingly accepted that significantly improving plastic recycling does not begin with the collection, sorting, or recycling of the waste, but rather with product design, taking into account their recyclability. This strategy is in literature often referred to as the "design for recycling" concept. ${ }^{52}$ Various guidelines already exist, yet these guidelines are often limited to general statements (e.g., using single-polymer packaging designs whenever possible) and mainly focus on mechanical recycling. ${ }^{53-55}$ Based on the data presented in this study, guidelines for packaging design, plastic collection, sorting, pretreatment, and recycling via mechanical recycling and pyrolysis can be improved and elaborated, tailored on the specific composition of various packaging types. This will be key toward improved plastic recycling rates and, finally, toward a more circular economy for plastics.

\section{ASSOCIATED CONTENT}

\section{SI Supporting Information}

The Supporting Information is available free of charge at https://pubs.acs.org/doi/10.1021/acs.est.0c03371.

Additional information for materials and methods; statistical data (Figures S1 and S2); POM, FTIR, and DSC spectra (Figures S3 and S4); descriptive overview of the analyzed representative products and their corresponding waste category (Table S1); calculation of the polymer composition of a hypothetical poly- material packaging item (Table S2); operational parameters (Table S3); emission line, viewing mode, LOD, and LOQ (Table S4); share of multilayer material per separable component and per packaging type (Table S5); and average \pm standard deviation (Tables S6-14); (PDF)

\section{AUTHOR INFORMATION}

\section{Corresponding Author}

Steven De Meester - Laboratory for Circular Process Engineering (LCPE), Department of Green Chemistry and Technology, Faculty of Bioscience Engineering, Ghent University, B-8500 Kortrijk, Belgium; 이이이.org/0000-0002-52463918; Email: Steven.Demeester@ugent.be

\section{Authors}

Martijn Roosen - Laboratory for Circular Process Engineering (LCPE), Department of Green Chemistry and Technology, Faculty of Bioscience Engineering, Ghent University, B-8500 Kortrijk, Belgium; 이이. orcid.org/0000-0002-9551-4658

Nicolas Mys - Laboratory for Circular Process Engineering (LCPE), Department of Green Chemistry and Technology, Faculty of Bioscience Engineering and Center for Polymer and Material Technologies (CPMT), Department of Materials, Textiles and Chemical Engineering, Faculty of Engineering and Architecture, Ghent University, B-8500 Kortrijk, Belgium

Marvin Kusenberg - Laboratory for Chemical Technology (LCT), Department of Materials, Textiles and Chemical Engineering, Faculty of Engineering \& Architecture, Ghent University, Zwijnaarde B-9052, Belgium

Pieter Billen - Intelligence in Processes, Advanced Catalysts \& Solvents (iPRACS), Faculty of Applied Engineering, University of Antwerp, B-2020 Antwerp, Belgium

Ann Dumoulin - Laboratory for Circular Process Engineering (LCPE), Department of Green Chemistry and Technology, Faculty of Bioscience Engineering, Ghent University, B-8500 Kortrijk, Belgium

Jo Dewulf - Sustainable Systems Engineering (STEN), Department of Green Chemistry and Technology, Faculty of Bioscience Engineering, Ghent University, B-9000 Ghent, Belgium

Kevin M. Van Geem - Laboratory for Chemical Technology (LCT), Department of Materials, Textiles and Chemical Engineering, Faculty of Engineering \& Architecture, Ghent University, Zwijnaarde B-9052, Belgium; 이이이.org/00000003-4191-4960

Kim Ragaert - Center for Polymer and Material Technologies (CPMT), Department of Materials, Textiles and Chemical Engineering, Faculty of Engineering and Architecture, Ghent University, Zwijnaarde B-9052, Belgium

Complete contact information is available at:

https://pubs.acs.org/10.1021/acs.est.0c03371

\section{Notes}

The authors declare no competing financial interest.

\section{ACKNOWLEDGMENTS}

This work was financially supported by the Catalisti-ICON project (HBC.2018.0262) MATTER (Mechanical and Thermochemical Recycling of mixed plastic waste) funded by Flanders Innovation \& Entrepreneurship (VLAIO). 


\section{REFERENCES}

(1) Lebreton, L. C. M.; van der Zwet, J.; Damsteeg, J. W.; Slat, B.; Andrady, A.; Reisser, J. River Plastic Emissions to the World's Oceans. Nat. Commun. 2017, 8, No. 15611.

(2) Lebreton, L.; Andrady, A. Future Scenarios of Global Plastic Waste Generation and Disposal. Palgrave Commun. 2019, 5, No. 6.

(3) Zheng, J.; Suh, S. Strategies to Reduce the Global Carbon Footprint of Plastics. Nat. Clim. Change 2019, 9, 567.

(4) Jia, L.; Evans, S.; van der Linden, S. Motivating Actions to Mitigate Plastic Pollution. Nat. Commun. 2019, 10, No. 4582.

(5) European Commission. Commission Regulation (EU) 2018/848 on Organic Production and Labelling of Organic Products and Repealing Council Regulation (EC) No 834/2007, 2018.

(6) Garcia, J. M.; Robertson, M. L. The Future of Plastics Recycling: Chemical Advances Are Increasing the Proportion of Polymer Waste That Can Be Recycled. Science 2017, 358, 870-872.

(7) Ragaert, K.; Delva, L.; Van Geem, K. Mechanical and Chemical Recycling of Solid Plastic Waste. Waste Manage. 2017, 69, 24-58.

(8) Huysveld, S.; Hubo, S.; Ragaert, K.; Dewulf, J. Advancing Circular Economy Benefit Indicators and Application on Open-Loop Recycling of Mixed and Contaminated Plastic Waste Fractions. J. Clean. Prod. 2019, 211, 1-13.

(9) European Commission. Commission Regulation (EU) No 2011/ 10 on Plastic Materials and Articles Intended to Come into Contact with Food, 2011.

(10) Garcia, P. S.; Scuracchio, C. H.; Cruz, S. A. Effect of Residual Contaminants and of Different Types of Extrusion Processes on the Rheological Properties of the Post-Consumer Polypropylene. Polym. Test. 2013, 32, 1237-1243.

(11) Rahimi, A. R.; Garciá, J. M. Chemical Recycling of Waste Plastics for New Materials Production. Nat. Rev. Chem. 2017, 1, No. 0046.

(12) Zhang, Z.; Gora-Marek, K.; Watson, J. S.; Tian, J.; Ryder, M. R.; Tarach, K. A.; López-Pérez, L.; Martínez-Triguero, J.; MeliánCabrera, I. Recovering Waste Plastics Using Shape-Selective NanoScale Reactors as Catalysts. Nat. Sustain. 2019, 2, 39-42.

(13) Ügdüler, S.; Van Geem, K. M.; Roosen, M.; Delbeke, E. I. P.; De Meester, S. Challenges and Opportunities of Solvent-Based Additive Extraction Methods for Plastic Recycling. Waste Manag. 2020, 104.

(14) Brouwer, M.; Picuno, C.; Thoden van Velzen, E. U.; Kuchta, K.; De Meester, S.; Ragaert, K. The Impact of Collection Portfolio Expansion on Key Performance Indicators of the Dutch Recycling System for Post-Consumer Plastic Packaging Waste, a Comparison between 2014 and 2017. Waste Manag. 2019, 100, 112-121.

(15) Dahlbo, H.; Poliakova, V.; Mylläri, V.; Sahimaa, O.; Anderson, R. Recycling Potential of Post-Consumer Plastic Packaging Waste in Finland. Waste Manag. 2018, 71, 52-61.

(16) Braunegg, G.; Bona, R.; Schellauf, F.; Wallner, E. Solid Waste Management and Plastic Recycling in Austria and Europe. Polym. Plast. Technol. Eng. 2004, 43, 1755-1767.

(17) Gala, A.; Guerrero, M.; Serra, J. M. Characterization of PostConsumer Plastic Film Waste from Mixed MSW in Spain: A Key Point for the Successful Implementation of Sustainable Plastic Waste Management Strategies. Waste Manag. 2020, 111, 22-33.

(18) Foschi, E.; D'Addato, F.; Bonoli, A. Plastic Waste Management: A Comprehensive Analysis of the Current Status to Set up an afterUse Plastic Strategy in Emilia-Romagna Region (Italy). Environ. Sci. Pollut. Res. 2020, 231, 1-14.

(19) Eriksen, M. K.; Astrup, T. F. Characterisation of SourceSeparated, Rigid Plastic Waste and Evaluation of Recycling Initiatives: Effects of Product Design and Source-Separation System. Waste Manag. 2019, 87, 161-172.

(20) Patel, M.; Von Thienen, N.; Jochem, E.; Worrell, E. Recycling of Plastics in Germany. Resour. Conserv. Recycl. 2000, 29, 65-90.

(21) Statista. Leading food retailers in Belgium 2017, by market share. https://www.statista.com/statistics/978630/leading-foodretailers-in-belgium-by-market-share/ (accessed Apr 14, 2020).
(22) Simoneau, C.; Hoekstra, E.; Mieth, A. Guidance for the Identification of Polymers in Multilayer Films Used in Food Contact Materials: User Guide of Selected Practices to Determine the Nature of Layers, European Commission JRC Technical Reports, 2016.

(23) Kaiser, K.; Schmid, M.; Schlummer, M. Recycling of PolymerBased Multilayer Packaging: A Review. Recycling 2017, 3, No. 1.

(24) Kim, Y. T.; Min, B.; Kim, W. K. General Characteristics of Packaging Materials for Food System. In Food Science and Technology, Han, J. H. B. T.-I. inF. P., Ed.; Academic Press: San Diego, 2014; Chapter 2, pp13-35.

(25) van Bruggen, E. P. A.; Koster, R. P.; Picken, S. J.; Ragaert, K. Influence of Processing Parameters and Composition on the Effective Compatibilization of Polypropylene-Poly(Ethylene Terephthalate) Blends. Int. Polym. Process. 2016, 31, 179-187.

(26) Hubo, S.; Delva, L.; Van Damme, N.; Ragaert, K. Blending of Recycled Mixed Polyolefins with Recycled Polypropylene: Effect on Physical and Mechanical Properties, AIP Conference Proceedings, 2016; p 1779.

(27) Utracki, L. A.; Wilkie, C. A. Polymer Blends Handbook; Kluwer Academic Publishers: Dordrecht, 2014.

(28) Huysman, S.; De Schaepmeester, J.; Ragaert, K.; Dewulf, J.; De Meester, S. Performance Indicators for a Circular Economy: A Case Study on Post-Industrial Plastic Waste. Resour. Conserv. Recycl. 2017, $120,46-54$.

(29) Van Belle, A. V.; Demets, R.; Mys, N.; Van Kets, K. V.; Dewulf, J.; Van Geem, K. V.; De Meester, S. D.; Ragaert, K. Microstructural Contributions of Different Polyolefins to the Deformation Mechanisms of Their Binary Blends. Polymers 2020, 12, No. 1171.

(30) Eriksen, M. K.; Pivnenko, K.; Olsson, M. E.; Astrup, T. F. Contamination in Plastic Recycling: Influence of Metals on the Quality of Reprocessed Plastic. Waste Manag. 2018, 79, 595-606.

(31) European Commission. Directive 2011/65/EU of The European Parliament and of the Council of 8 June 2011 on the Restriction of the Use of Certain Hazardous Substances in Electrical and Electronic Equipment, 2011.

(32) Miskolczi, N.; Bartha, L.; Deák, G.; Jóver, B. Thermal Degradation of Municipal Plastic Waste for Production of Fuel-like Hydrocarbons. Polym. Degrad. Stab. 2004, 86, 357-366.

(33) Dijkmans, T.; Pyl, S. P.; Reyniers, M. F.; Abhari, R.; Van Geem, K. M.; Marin, G. B. Production of Bio-Ethene and Propene: Alternatives for Bulk Chemicals and Polymers. Green Chem. 2013, 15, 3064-3076.

(34) Sharuddin, S. D. A.; Abnisa, F.; Daud, W. M. A. W.; Aroua, M. K. A Review on Pyrolysis of Plastic Wastes. Energy Convers. Manag. 2016, 115, 308-326.

(35) Grause, G.; Buekens, A.; Sakata, Y.; Okuwaki, A.; Yoshioka, T. Feedstock Recycling of Waste Polymeric Material. J. Mater. Cycles Waste Manag. 2011, 13, 265-282.

(36) Phuphuakrat, T.; Namioka, T.; Yoshikawa, K. Tar Removal from Biomass Pyrolysis Gas in Two-Step Function of Decomposition and Adsorption. Appl. Energy 2010, 87, 2203-2211.

(37) Xue, Y.; Zhou, S.; Brown, R. C.; Kelkar, A.; Bai, X. Fast Pyrolysis of Biomass and Waste Plastic in a Fluidized Bed Reactor. Fuel 2015, 156, 40-46.

(38) Trubetskaya, A.; Brown, A.; Tompsett, G. A.; Timko, M. T.; Kling, J.; Broström, M.; Andersen, M. L.; Umeki, K. Characterization and Reactivity of Soot from Fast Pyrolysis of Lignocellulosic Compounds and Monolignols. Appl. Energy 2018, 212, 1489-1500.

(39) Wang, X.; Jin, Q.; Zhang, J.; Li, Y.; Li, S.; Mikulčić, H.; Vujanović, M.; Tan, H.; Duić, N. Soot Formation during Polyurethane (PU) Plastic Pyrolysis: The Effects of Temperature and Volatile Residence Time. Energy Convers. Manag. 2018, 164, 353362.

(40) Reyniers, P. A.; Vandewalle, L. A.; Saerens, S.; de Smedt, P.; Marin, G. B.; Van Geem, K. M. Techno-Economic Analysis of an Absorption Based Methanol to Olefins Recovery Section. Appl. Therm. Eng. 2017, 115, 477-490.

(41) Symoens, S. H.; Olahova, N.; Munoz Gandarillas, A. E.; Karimi, H.; Djokic, M. R.; Reyniers, M. F.; Marin, G. B.; Van Geem, K. M. 
State-of-the-Art of Coke Formation during Steam Cracking: AntiCoking Surface Technologies. Ind. Eng. Chem. Res. 2018, 57, 1611716136.

(42) Grause, G.; Hirahashi, S.; Toyoda, H.; Kameda, T.; Yoshioka, T. Solubility Parameters for Determining Optimal Solvents for Separating PVC from PVC-Coated PET Fibers. J. Mater. Cycles Waste Manag. 2017, 19, 612-622.

(43) Serrano, D. P.; Aguado, J.; Escola, J. M. Developing Advanced Catalysts for the Conversion of Polyolefinic Waste Plastics into Fuels and Chemicals. ACS Catal. 2012, 2, 1924-1941.

(44) Abnisa, F.; Wan Daud, W. M. A. A Review on Co-Pyrolysis of Biomass: An Optional Technique to Obtain a High-Grade Pyrolysis Oil. Energy Convers. Manag. 2014, 87, 71-85.

(45) Eunomia. Plastic Packaging: Shedding Light on the UK Data; Bristol, UK, 2018.

(46) Jang, Y.-C.; Lee, G.; Kwon, Y.; Lim, J.-h.; Jeong, J.-h. Recycling and Management Practices of Plastic Packaging Waste towards a Circular Economy in South Korea. Resour. Conserv. Recycl. 2020, 158, No. 104798.

(47) Subramanian, P. M. Plastics Recycling and Waste Management in the US. Resour. Conserv. Recycl. 2000, 28, 253-263.

(48) Brouwer, M. T.; Thoden van Velzen, E. U.; Augustinus, A.; Soethoudt, H.; De Meester, S.; Ragaert, K. Predictive Model for the Dutch Post-Consumer Plastic Packaging Recycling System and Implications for the Circular Economy. Waste Manag. 2018, 71, $62-85$.

(49) WRAP Composition of Plastic Waste Travelling through the English and Welsh Sorting Infrastructure, Prepared by Resource Futures; Banbury, 2018.

(50) Götze, R.; Pivnenko, K.; Boldrin, A.; Scheutz, C.; Astrup, T. F. Physico-Chemical Characterisation of Material Fractions in Residual and Source-Segregated Household Waste in Denmark. Waste Manag. 2016, 54, 13-26.

(51) Horodytska, O.; Valdés, F. J.; Fullana, A. Plastic Flexible Films Waste Management - A State of Art Review. Waste Manag. 2018, 77, 413-425.

(52) Hahladakis, J. N.; Iacovidou, E. An Overview of the Challenges and Trade-Offs in Closing the Loop of Post-Consumer Plastic Waste (PCPW): Focus on Recycling. J. Hazard. Mater. 2019, 380, No. 120887.

(53) The Association of Plastic Recyclers. APR Design Guide for Plastics Recyclability; Washington, DC, 2019.

(54) Borealis, A. G. Polyolefin Packaging Design 10 Codes of Conduct for Design for Recyclability; Vienna, 2019.

(55) Plastics Recyclers Europe. Design for Recycling Guidelines; Brussels, 2018. 